\title{
The Impact of State Corporate Taxes on FDI Location
}

\author{
Claudio Agostini * $\quad$ Soraphol Tulayasathien ${ }^{\dagger}$
}

September $2003 \ddagger$

\begin{abstract}
This paper examines the effects of state corporate income taxes on the location of foreign direct investment, taking into account the state governments' behavior when setting taxes.

Ignoring the tax setting behavior of states may bias the estimate of the tax effects on foreign direct investment. States have a set of characteristics that influence investors' decisions, some of them are not observable by a researcher but states take them into account when they set taxes. States can also act strategically with respect to other states when setting taxes. The former behavior bias the estimated tax effects because it creates correlation between the error term and the tax rate. The latter behavior directly implies an endogenous tax rate.

We adapt a discrete choice model of differentiated products to estimate the tax effects. This approach allows us at the same time to control for the outside options of investors and to use instrumental variables to solve the problem of tax endogeneity. We find the tax elasticity to be consistently around -1 .
\end{abstract}

JEL: F23, H25, H71, H73, H87.

Keywords: Foreign Direct Investment, State Corporate Income Taxes, Tax Endogeneity.

\section{Introduction}

Although corporate income taxes should theoretically influence investors' decisions about where to locate their investments, empirical studies of the tax effects show mixed results. Several articles

\footnotetext{
${ }^{*}$ Department of Economics, Alberto Hurtado University, Santiago, Chile. Email: agostini@uahurtado.cl

${ }^{\dagger}$ E-mail: soraphol@umich.edu

${ }^{\ddagger}$ We are grateful to Julie Cullen, Jim Hines, Illoong Kwon, Jim Levinsohn, and Joel Slemrod for helpful comments and suggestions. The remaining errors are ours.
} 
in the literature have found that taxes have no influence on investment location at all $^{1}$; some few articles have found a consistent and robust negative effect, and a few others have found a positive impact (see Carlton (1983), Coughlin, Terza, and Arrondee (1991), Luger and Shetty (1985), Hines (1996), and Papke (1991))..$^{2}$

The empirical work has mainly focused on the demand side of this story, estimating then a reduced form model. Our view and the main motivation for this paper are that we can obtain an important insight by also considering the supply side of the problem. By demand and supply sides, we mean foreign firms as demanders for U.S. locations and U.S. states as suppliers of the locations for investment.

Foreign investors, on the one hand, compare different characteristics (including the state corporate income tax) of each location before deciding where to invest, considering for this purpose also locations outside of the U.S.. State governments, on the other hand, want to attract investment perhaps because of its positive effects on income growth and employment. There are several characteristics that each state supplies to investors, some of them are inherent to the state, such as natural resources and geography, while some others are set by the states themselves, corporate income taxes and the level of public goods for example. Some of these states' characteristics are unobservable by the researcher, like reputation and bureaucracy or corruption levels for example, but they are considered by investors when they choose where to invest and by state governments when they set taxes. This is the supply side of the story, which if it is not taken into account in

\footnotetext{
${ }^{1}$ In this paper we will argue that tax endogeneity may dampen the overall estimated tax effects; consequently neglecting tax setting behavior may lead to insignificant estimates of the tax effects (even if the true effect is negative).

${ }^{2}$ Wasylenko (1997) reviews recent research on the effects state taxes have on economic development and reports a summary of econometric results of tax effects on business location.
} 
the empirical work may lead to biased and inconsistent estimates of the tax effects on investment location.

The process of setting taxes by state governments can also involve strategic interaction among states. There is one strand of the public finance literature that has looked at the influence of neighboring states' (countries') decisions (Besley and Case(1995); Case, Hines, and Rosen (1993); Rork(2000)). Case, Hines, and Rosen (1993), for example, test the notion that state governments' expenditures depend on the spending of similar states. They estimate that a dollar increase in a state's neighbors expenditures per capita increases its own expenditure by over 70 cents. This illustrates how decisions among states interrelate and how important it is to take this interrelation into account. For example, if Florida were to lower its tax rate in order to attract FDI, Alabama may respond by cutting its tax rate; consequently, the increase in FDI into Florida may not be as large. By ignoring tax competition in the analysis, the estimated tax effects may be biased since it also embeds the interaction among states. As it will be explained when we present the model, even in the case where there is no strategic interaction at all, there may be a bias due to the correlation between the error term of the demand for investment location and some unobserved determinants of the tax setting process. For example, the discovery of an oil well in Alaska results in FDI inflow into Alaska for two different reasons. First, Alaska is now more attractive to foreign investors (at least to investors in the oil industry). Second, Alaska may lower its tax rate as the revenue from the oil well may relieve some pressure of the Alaskan government to raise revenue from FDI. In this example, the tax elasticity would be biased upward (towards zero).

This paper, then, examines the effects of corporate income taxes on the location of FDI in the U.S. states, considering the endogeneity of the tax rates and the fact that foreign investors have 
outside options (investment locations outside U.S. states). We focus on FDI in the U.S. mainly for three reasons. First, FDI has become increasingly important in the United States. Outlays by foreign direct investors to establish businesses in the United States have increased from $\$ 15,333$ millions in 1992 to $\$ 335,629$ millions in 2000 . U.S. businesses established by foreign direct investors in 2000 had total assets of $\$ 482.02$ billion and employed 770,000 people. Second, for foreign investors, the corporate income tax is one of the relevant state characteristics to consider in their investment decision. ${ }^{3}$ Third, we have access to surveys on foreign direct investment in the U.S. by state and by source country for 5 years in a span of 23 years, which provides enough variation in tax rates and state characteristics that allows the identification of tax effects.

In this paper, we use a structural model to estimate the effects of corporate taxes on investment location taking into account the tax setting behavior of state governments. The rest of the paper is divided as follows. Section 2 presents a model of investors' decisions for location of investment. Adapting techniques from the discrete-choice literature, we present a model of aggregated investment demand that can be used to estimate "unbiased" and consistent tax effects on investment location. Section 3 discuss the states' tax setting process. Section 4 describes the data. Section 5 shows the empirical results, and Section 6 concludes.

\section{A Model of Demand for Investment Location}

A foreign investor can choose among 50 different U.S. states and an outside location to locate his investment. The presence of the outside location is extremely important. Without an outside

\footnotetext{
${ }^{3}$ The evidence in the literature has shown that manufacturing firms are more likely to locate or start up in states with low corporate taxes. See Bartik (1991) and Ladd (1998) for a review of the literature.
} 
investment alternative, a uniform increase in tax rates by all states would not change the amount of investment in each state. ${ }^{4}$

For the purpose of deciding where to invest, an investor will compare several different characteristics among states, one of which is the corporate tax rate. The tax rate is the price in the demand for investment function ${ }^{5}$, but given that different states have different characteristics, we have to think about different locations as differentiated products (think about each state as a different brand of the same product).

If the investor decides to invest in state $j$, he maximizes his profits by choosing the level of investment as well as the quantity of labor hired in state $j$.

The investor's problem, conditional on investing in state $j$, can be written as follows:

$$
\begin{aligned}
\max _{L_{i s j}, F D I_{i s j}} \pi_{i s j} & =\left(P Q_{i s j}-w_{j} L_{i s j}-r_{i} F D I_{i s j}-F_{j}\right)\left(1-t_{j}\right) \\
\text { s.t. } \quad Q_{i s j} & =f\left(F D I_{i s j}, L_{i j}\right)
\end{aligned}
$$

where:

$$
\pi_{i s j}=\text { profits of investor } i \text { from country } s \text { if he invests in state } j
$$

\footnotetext{
${ }^{4}$ Furthermore, without an outside investment alternative a uniform increase in tax rates by all states would improve the states' welfare. With the outside investment alternative, states cannot uniformly increase their tax rates without losing some of the investment elsewhere; consequently, a uniform increase in tax rates may not increase welfare. Huber (1999) shows that if the wealth distribution is egalitarian, a coordinated increase in capital taxes does not affect welfare. For non-egalitarian wealth distributions, welfare can increase or decrease depending on the redistributive impact of a higher capital tax.

Previous empirical studies of the tax effects ignore the issue of outside investment alternatives in their estimation strategy. This may result in a biased estimate of the tax effects.

${ }^{5}$ Depending on how it is specified, the tax rate is a price per unit of profits or per unit of capital invested in a specific state.
} 
$P=$ price of the product produced by the investor

$Q_{i s j}=$ quantity of the product sold

$w_{j}=$ wage rate in state $j$

$L_{i s j}=$ quantity of labor hired by the investor in state $j$

$r_{i}=$ opportunity cost of capital for investor $i^{6}$

$F D I_{i s j}=$ quantity of capital invested by the investor in state $j$

$t_{j}=$ corporate tax rate in state $j$

$F_{j}=$ fixed costs of production

The production function $f\left(F D I_{i s j}, L_{i s j}\right)$ is assumed to be constant returns to scale. The firstorder conditions of this maximization problem are: ${ }^{7}$

$$
\begin{aligned}
& L_{i s j}: \quad P \frac{\partial f}{\partial L_{i s j}}-w_{j}=0 \\
& F D I_{i s j}: \quad P \frac{\partial f}{\partial F D I_{i s j}}-r_{i}=0
\end{aligned}
$$

Using the first-order conditions, we can write the conditional profit function for the investor $i$ from country $s$ who invests in state $j$ as follows:

$$
\pi_{i s j}^{*}\left(P, r_{i}, w_{j}, t_{j}\right)
$$

\footnotetext{
${ }^{6}$ This is the return on capital the investor would receive if he invests in an alternative location $\left(r_{i}=\max _{k \neq j}\left\{r_{k}\right\}\right)$.

${ }^{7}$ Alternatively, we could have speficied the investor's problem as: $\max _{L_{i s j}, F D I_{i s j}} \pi_{i s j}=P Q_{i s j}-w_{j} L_{i s j}-r_{i} F D I_{i s j}\left(1+t_{j}\right)-F_{j}$

Under this specification, the corporate tax rate has an impact on the optimal amount of capital and labor used. For our purposes, it will still affect the level of profits obtained, and therefore, the place where the investor invests.
} 
For given values of $P, r_{i}, w_{j}$ and $t_{j}$ the profit function will determine the actual profits an investor $i$ from country $s$ will get if he invests in state $j$. Therefore, using the conditional profit functions, a foreign investor can compare the profits he would get from investing in various locations. Hence, the investor $i$ from country $s$ will choose to invest in state $j$ if and only if the investment yields the greatest profit among all investment alternatives. ${ }^{8},{ }^{9}$ That is,

$$
\pi_{i s}^{*}=\max \left\{\pi_{i s n}^{*} ; n=0, \ldots, 50\right\}
$$

Where $n=0$ represents the outside option (an alternative investment location outside the 50 U.S. states).

Adding investment choices by all investors yields the aggregated demand function. ${ }^{10}$

\subsection{Discrete-Choice Approach}

The estimation of a demand function for differentiated products is a complex task, mainly because of the large number of parameters that need to be estimated. In the case of $N$ different products (50 states in this case), you have to estimate $N$ own price elasticities and $N(N-1)$

\footnotetext{
${ }^{8}$ We have assumed that each investor solves 51 different maximization problems (one for each state and one for the outside option), compares the 51 profit levels that result from each maximization and then decides to invest in one and only one location. The reasons to use this approach will be explained in the next section.

${ }^{9} \mathrm{It}$ is a fact that several foreign investors have investments in more than one state. The discreteness of choice assumption has been defended in the literature saying that investors invest, in this case, in plant and equipment in one state at a time. Therefore, over time, they have investments in several states but when they decide about a particular project, they choose only one state for it. Even though this may be a reasonable assumption in the context of the data we use for the empirical part, we will only claim something less restrictive, which is that this model is a good approximation for the true decison process of investors.

${ }^{10}$ We are aware that this is just an approximation to the real aggregated demand function. This approximation might not be necessarily a smooth continuous function, but the alternatives are either to use a homogeneous product approach or, as it will be discussed in the next section, to have a huge dataset that allows the estimation of all the parameters involved. We think that the former approach introduces a bias that is worse than this approximation; the latter, on the other hand, is not possible with the data available.
} 
cross-price elasticities. ${ }^{11}$ This implies an over-parameterization of the econometric model, which makes it impossible to estimate in most cases. We solve this problem modeling product choice explicitly in our estimation of the demand system. This approach is based on McFadden's (1974) work, which develops models of discrete choice to individual's choice of products. ${ }^{12}$

A second issue in the estimation of a demand function under product differentiation is the heterogeneity of consumers (investors in this case); unless investors have different preferences or production functions, all of them would invest in the same location. ${ }^{13}$ There are different approaches to model heterogeneity depending on the assumptions regarding the distribution of individual attributes. The Logit, Nested Logit, and Generalized Extreme Value models, for example, assume that heterogeneity enters the model only through a random shock. They also assume a distribution of these shocks and a different degree of correlation among them. Even though this approach places some restrictions on the elasticities of demand, which will be explained in the next section, it is more tractable and, therefore, is the one we will use. ${ }^{14}$

In this section, we follow Nevo's (2000) approach to derive the aggregated demand for investment by explicitly aggregating discrete investment decisions of foreign investors. For this purpose, we first define the profit function of investor $i$ from the country-year combination $t$ for investing in

\footnotetext{
${ }^{11}$ Thus, there are $50 \times 50=2500$ elasticities to be estimated in our case. If we impose symmetry in our elasticity matrix, the number of elasticities we would need to estimate would be reduced to: $50+\frac{50(50-1)}{2}=1275$.

${ }^{12}$ The following are good examples of the use of the discrete-choice framework. McFadden (1974) uses his discretechoice model to examine individual choice of products. Berry, Levinsohn, and Pakes (1995, 1998) study strategic interactions in price setting among U.S. automakers. Nevo (2001) estimates demand and market power in the readyto-eat cereal industry.

${ }^{13}$ In this context, "heterogeneity of investors" basically means that investors have different profit functions. This can be due to different tastes (with respect to state characteristics), different production functions, or production in different economic sectors.

${ }^{14}$ The alternative is to use a Random Coefficients Model that allows for more general substitution patterns. The use of that approach not only would require additional information about the distribution of investors heterogeneity, which we do not have, but also would require the use of simulation methods to be solved.
} 
state $j::^{15}$

$$
\pi_{i j t}^{*}\left(X_{j t}, \xi_{j t}, t_{j t}, v_{i}, \theta\right)
$$

where $X$ is a k-dimensional vector of observed state characteristics, $\xi$ are unobserved state characteristics, $t$ is the state corporate tax rate, $v$ are investor's individual characteristics, and $\theta$ are unknown parameters. Here we are assuming that all investors face the same state characteristics, particularly the same tax rate. ${ }^{16}$

In this model, we assume the following specification for the profit function: ${ }^{17}$

$$
\pi_{i j t}^{*}=-\alpha t_{j t}+X_{j t} \beta+\xi_{j t}+\varepsilon_{i j t}
$$

We also need to consider the possibility that the investor may decide not to invest in any of the 50 states at all. Theoretically, the outside option in this case is to invest in any other country of the world; the profit function from this option is:

$$
\pi_{i o t}^{*}\left(X_{o t}, \xi_{o t}, t_{o t}, v_{i}, \theta\right)
$$

The functional form for the profit function of the outside option is:

\footnotetext{
${ }^{15}$ There are $t=1, \ldots, I_{t}$ investors, $j=1, \ldots, 50$ states, and $t=1, \ldots, 35$ source country-year combinations ( 5 years, 3 of them with 8 countries, one with 7 countries, and one with 4 countries). See the data description in section 4 .

${ }^{16}$ If different investors face different tax rates when they are investing in the same state, then tax rates would be correlated with the error term (due to measurement error). This problem can be corrected using IV.

${ }^{17}$ The model is relatively general and with minor adjustments can be used with different specifications. The linear and loglinear cases basically require the absence of wealth effects. That is the case when you consider maximization of profits, but it is not always true for utility maximization.
} 


$$
\pi_{i o t}^{*}=\xi_{o t}+\varepsilon_{i o t}
$$

The mean profit of the outside option is not identified without either making more assumptions or normalizing one of the U.S. states. We normalize $\xi_{\text {ot }}$ to zero. Defining $\theta=(\alpha, \beta)$, the profit function can be expressed as:

$$
\pi_{i j t}^{*}=\delta_{j t}\left(X_{j t}, t_{j t}, \xi_{j t} ; \theta\right)+\varepsilon_{i s j t}
$$

where

$$
\delta_{j t}=-\alpha t_{j t}+X_{j t} \beta+\xi_{j t}
$$

In this model, investors are assumed to invest in one state, the one that gives them the highest profits (return). ${ }^{18}$ One investor is defined as a vector of state specific shocks, $\left(\varepsilon_{i s o t}, \varepsilon_{i s 1 t}, \ldots, \varepsilon_{i s 50 t}\right)$. Hence, the set of individual characteristics that lead to the choice of state $j$ can be defined as:

$$
A_{j t}\left(\delta_{. t}\right)=\left\{\varepsilon_{i . t} \mid \pi_{i j t} \geq \pi_{i l t} \forall l=0 \ldots 50\right\}
$$

Then, for a given set of parameters, we can predict the FDI share of each state in each year, as a function of state characteristics, tax rates, and unknown parameters. If ties occur with zero probability, the FDI share of the state $j$ as a function of the mean profit levels of all the 51 locations given the parameters is:

\footnotetext{
${ }^{18}$ This assumption is needed; otherwise, we would have to compare every single combination of different states, and that makes the model not tractable (the number of parameters increases dramatically). Hendel (1999) has relaxed this assumption in some way, but it is not applicable in the context of this problem and the data we have.
} 


$$
s_{j t}\left(\delta_{. t}\right)=\int_{A_{j t}} d P(\varepsilon)
$$

where $P(\cdot)$ represents the population distribution function.

The estimation strategy is to choose parameters that minimize the distance between the FDI shares predicted by the model and the observed ones ${ }^{19}$, which implies to solve the implicit system of equations:

$$
s_{. t}\left(X_{. t}, t_{. t}, \delta_{. t} ; \theta\right)=S_{. t}
$$

where $s_{. t}(\cdot)$ are the predicted FDI shares define by equation (12), and $S_{. t}$ are the observed FDI shares.

This strategy gives estimates of the parameters that determine the distribution of investors' attributes, but it does not solve the correlation between tax rates and unobserved state characteristics.

The use of a Logit demand model allow us to solve the problem of over-parameterization projecting the states into a space of characteristics and the main assumption we have been relying on, is that investors' heterogeneity enters only through a separable additive random shock $\varepsilon_{i j t}$. Up to this point, the model we have presented here is very general and no more restrictive than other models used in the literature. However, a second assumption of the Logit model is that $\varepsilon_{i j t}$ is i.i.d. and is distributed according to a Type I extreme value distribution. These latter restrictions, which are made in order to compute the integral in equation (12), are more restrictive and have

\footnotetext{
${ }^{19}$ By making assumptions on the distribution of $\varepsilon$, the integral of equation (12) can be calculated analytically.
} 
implications for the tax elasticities of the demand equation.

The state $j$ 's share of FDI from country-year combination $t$ under this restrictions is:

$$
s_{j t}=\frac{\exp \left(-\alpha t_{j t}+X_{j t} \beta+\xi_{j t}\right)}{1+\sum_{k=0}^{50} \exp \left(-\alpha t_{k t}+X_{k t} \beta+\xi_{k t}\right)}
$$

Now, equation (13) can be solved analytically to get:

$$
\delta_{j t}=\ln \left(S_{j t}\right)-\ln \left(S_{o t}\right)
$$

where $S_{i j t}$ and $S_{i o t}$ are the observed FDI shares in state $j$ and in outside investment option respectively.

Thus, the demand equation to be estimated becomes:

$$
\ln \left(S_{j t}\right)-\ln \left(S_{o t}\right)=-\alpha t_{j t}+X_{j t} \beta+\xi_{j t}
$$

The tax elasticity of the FDI shares $s_{j t}$ defined by equation (14) is: ${ }^{20}$

$$
\eta_{j t}=\frac{\partial s_{j t}}{\partial t_{j t}} \frac{t_{j t}}{s_{j t}}=-\alpha t_{j t}\left(1-s_{j t}\right)
$$

Summarizing, the Logit model allows us to solve the over-parameterization of the model but does not solve the endogeneity of the tax rate $\left(\operatorname{cov}\left(t_{j t}, \xi_{j t}\right) \neq 0\right)$.

\footnotetext{
${ }^{20}$ It is important to note that the tax elasticity is driven by the functional form assumption about how the tax rate enters the profit function. If, for example, the profit function were log-linear, rather than linear, the implied elasticity would be roughly constant. We will discuss this possibility in the empirical part.
} 


\section{Tax Setting}

There are several models of tax setting in the literature and with minor modifications to any of them we could show why the corporate income tax rate is endogenous and how it bias the estimates of tax elasticities if the endogeneity is not considered. However, we will not present a specific tax setting model in this section for two reasons. First, it is beyond of the scope of this paper to estimate a structural tax setting equation of the state governments and draw conclusions from it. The main goal is to obtain a consistent estimator of the tax elasticity of foreign investment. Second, to use a specific model would not provide more insight about the endogeneity of the tax rate and its consequences on the estimation of the demand for investment, but would complicate the analysis and the results would be very specific to the model used.

In general, we can consider that a state government wants to maximize the welfare of its citizens and needs to finance the provision of public goods with taxes. In the case of the U.S. states governments, they mainly use sales, corporate income, and personal income taxes for this purpose. When setting their corporate income tax rate, the state governments probably consider how attractive the state is for investors, the benefits in terms of employment and income growth of attracting more investment to the state, the corporate income tax rates of their neighbors and their budget constraints (total revenue to be raised, revenue collected from sale and personal income taxes, etc.).

In the model of investment location presented in the previous section, a state is defined by a set of characteristics and some of those characteristics are not observed, though they influence investors' decisions (demand); therefore, they will be captured in the error term. States know those 
characteristics, and they take them into account when setting taxes. ${ }^{21}$ This implies that the tax rate is endogenous, and, therefore, the estimate of the tax effects on FDI ( $\alpha$ in equation (16)) might be biased. ${ }^{22}$

The total tax effect on FDI can be decomposed in two effects: the direct effect, and the indirect effect through observed $(X)$ and unobserved $(\xi)$ characteristics $^{23}$ :

$$
\frac{d F D I_{j}}{d t_{j}}=\frac{\partial F D I_{j}}{\partial t_{j}}+\frac{\partial F D I_{j}}{\partial \xi_{j}} \frac{d \xi_{j}}{d t_{j}}+\sum_{\forall k \neq j} \frac{\partial F D I_{j}}{\partial \xi_{k}} \frac{d \xi_{k}}{d t_{j}}+\frac{\partial F D I_{j}}{\partial X_{j}} \frac{d X_{j}}{d t_{j}}
$$

Since in estimating the tax effects, we control for observed characteristics on the right-hand-side of equation (16), the bias would only come from the unobserved factors. If any $\frac{d \xi}{d t}$ is different from zero, then estimating the tax effects on FDI without considering the unobservables would bias the estimated tax elasticity. The direction of the bias will depend on the signs of $\frac{\partial F D I}{\partial \xi}$ and $\frac{d \xi}{d t}$, which will depend on the type of unobservables. Let's consider some examples of unobservables:

-If $\xi$ is the tax abatements offered by other states, and there is tax competition, we would expect $\frac{d \xi_{k}}{d t_{j}}$ to be negative ${ }^{24}$. In this example, $\frac{\partial F D I_{j}}{\partial \xi_{k}}$ will also be negative. ${ }^{25}$ Consequently, ignoring tax competition would bias the estimated tax elasticity upward.

\footnotetext{
${ }^{21}$ These state characteristics are not observed by the researcher, but they are observed by investors and by state governments. Examples of these characteristics are: reputation of the state (honesty, bureaucracy, quality of services, quality of workers), and effects of advertisement (promotion of the state).

${ }^{22}$ Using a set of Montecarlo results, Berry (1994) has shown that estimation methods that ignore the endogeneity of prices (taxes) in the presence of unobserved product (state) characteristics can be severely misleading.

${ }^{23}$ Recall that from (12), foreign direct investment $(F D I)$ is a function of the corporate tax rate $t$, the observable state characteristics $X$ (public good provision, population, miles of road per area, real price of energy, etc.) and other unobserved characteristics $\xi$ (state reputation, non-tax investment incentives, other states' tax abatement programs, corruption level, etc.): $F D I=f(t, X, \xi)$.

${ }^{24}$ If a state reduce its corporate tax rate, other states may respond by increasing their tax abatement offers to foreign investors.

${ }^{25}$ If other states increase their tax abatement offers, the amount of FDI in the state would decrease.
} 
-If $\xi$ is the bad reputation for doing business in the state (e.g. corruption), we would expect $\frac{d \xi_{j}}{d t_{j}}$ to be negative. To compensate for the bad reputation, the state may want to reduce its corporate tax rate to attract investment. In this case, $\frac{\partial F D I_{j}}{\partial \xi_{j}}$ will be negative, states with bad reputation will receive less foreign direct investment, ceteris paribus. Consequently, ignoring the unobserved bad reputation would bias the estimated tax elasticity upward.

In the two previous examples, the estimated tax elasticity would be biased upward ${ }^{26}$. In general, the bias could be either upward or downward.

\subsection{Instrumental Variables}

One way to deal with the endogeneity bias is to use instrumental variables for the tax rate in the demand equation. Natural candidates to be used for this purpose are the exogenous variables in the tax setting equation that do not appear in the demand equation. Then, the natural instruments are some determinants of the state budget and tax setting process that are not correlated with unobserved determinants of foreign investment in the states.

If we look at budget practices across states, we can observe a good variation among them. On the one hand, there are different revenues and expenditures limitations. These limits constrain the annual growth of revenues or expenditures either to a fixed rate or to a one based on one or more of the following variables: inflation rate, population growth, growth of personal income, and ratio of revenue to personal income. On the other hand, states have a statutory or constitutional requirement to balance the budget. The two most common requirements are that the governor must submit a balanced budget and that the legislature must pass a balanced budget.

\footnotetext{
${ }^{26}$ If the true elasticity is negative the estimated elasticity would be biased toward zero (or positive).
} 
We think that these budget practices are good instruments for the tax rate. A potential concern would be that the observed correlation between budget rules and fiscal outcomes might reflect just a correlation of these two variables with an omitted third one, specifically citizens (voters) preferences for fiscal outcomes. However, the empirical literature on state budgeting and fiscal policy supports the hypothesis that budget rules matter and many of these studies have controlled for some measure of state voter preferences (Alt and Lowry (1994), Crain and Miller (1990), Bohn and Inman (1996), Elder (1992), Poterba (1994), Poterba (1995) and Rueben (1997)). Therefore, we use as instruments a set of dummy variables that reflect these different budget limits.

\section{Data}

The Bureau of Economic Analysis (BEA) publishes a benchmark survey of foreign direct investment in the U.S. roughly every five years. The data report FDI by state and by source country for major investing countries in the United States. These countries are Australia, Canada, France, Germany, Japan, the Netherlands, Switzerland, and the United Kingdom. ${ }^{27}$ The survey provides information on the value of property, plant, and equipment (PPE) owned by foreign U.S. affiliates in the manufacturing industry. ${ }^{28},{ }^{29}$

In the empirical work, we use the PPE data by state and source country for the years 1974, 1980, 1987, 1992 and 1997. As the outside option for investors, we use the total amount of investment in fixed capital (GFX) in their own countries. ${ }^{30},{ }^{31}$

\footnotetext{
${ }^{27}$ Investment outlays from these 8 countries accounted for $83.3 \%$ of the total foreign investment outlays in 2000 .

${ }^{28}$ Foreign direct investment in manufacturing represented $42.7 \%$ of the total FDI in the U.S. in 2000.

${ }^{29} \mathrm{An}$ affiliate is defined to be foreign-owned if one or more foreign investors own at least $10 \%$ percent each.

${ }^{30}$ That means $S_{j t}=\frac{P P E_{j t}}{\sum_{j} P P E_{j t}+G F X_{t}}$ and $S_{o t}=\frac{G F X_{t}}{\sum_{j} P P E_{j t}+G F X_{t}}$ in equation (16).

${ }^{31}$ We would have preferred to use FDI in the rest of the world as the outside option for each country, but the data
} 
The benchmark survey of 1974 has information only for four countries (Canada, Japan, Switzerland, and the United Kingdom) and the 1980 survey is missing Australia (it has data for 7 countries). Therefore, we have $1750(50 \times 3 \times 8+50 \times 7+50 \times 4)$ observations, of which only 9 of them are equal to zero. ${ }^{32}$ However, among these 1750 observations, 195 (11.1\%) are suppressed by the BEA for confidentiality reasons ${ }^{33}$, and $30(1.7 \%)$ are reported as being less than $\$ 500,000$ but no specific amount is provided. ${ }^{34}$ We deal with these missing data problems in three ways: first, the two types of observations are excluded from the sample; second, we estimate an Interval Regression using the 30 observations that we know represent a PPE of less than $\$ 500,000$; and third, we estimate an Interval Regression assuming that all missing observations represent PPE of less than $\$ 500,000$. The results are very similar across the three cases. ${ }^{35}$

There has been a long discussion in the literature about how to measure tax variables. The most common approaches are to use either the statutory tax rate for each tax or the ratio of revenues collected to income or population. The latter approach has the advantage that it captures aspects of both the nominal rate and the tax base, and in that sense it might be a better measure of the tax burden. In this case and following Hines (1996), we decided to use the top marginal statutory tax rate of the state corporate income tax. The main reason for using statutory tax rates is that

are not available for some of the years in the sample.

${ }^{32}$ This is relevant because an important assumption of our model is that we observe positive shares for all States. The reason is the need to invert the share equation and, therefore, the need of a one to one mapping from the mean profit level to the observed shares.

${ }^{33}$ The states with the highest number of missing observations are: Alaska (with 16), Idaho (with 13), and Montana (with 11). In terms of source countries they are: Switzerland (with 40) and Netherlands (with 39). 1980 is the year with most missing observations (with 61 ).

${ }^{34}$ The source countries with the highest number of observations of this type are: Japan (with 10) and Switzerland (with 13). In terms of states they are: Delaware and South Dakota (both with 4). 1974 is the year with most of this type of observations (with 19).

${ }^{35}$ We also estimated the same regressions dropping either the 5 states or the 3 source countries with most missing observations. The results were again very similar, but still we had around $8 \%$ of missing observations in both cases (instead of the $11 \%$ we have for the full sample). 
for newly locating firms or expanding businesses we think that the effect of taxes on the rate of return is better measured by the marginal rate of taxation on the investment or the user's cost of capital.

It is important to mention that we are omitting other tax rates and tax incentives from the analysis, and both are relevant on investors' decisions. In the case of other taxes omitted, probably property taxes are the most important ones. The problem is that property taxes are set at a local level and, therefore, it is difficult to characterize them at a state level. Furthermore, the BEA data is aggregated by state and by source country and therefore there is no information on where within each state the investment is located. This omission can introduce a bias in the estimation of the tax effect due to the potential correlation between the corporate tax rate and the error term (which includes the omitted tax rates); this provides another reason to use instrumental variables. In the case of tax incentives, they can play a major role in the location decision of a specific firm. It is a fact that several cities and/or states have offered and reached agreements on tax abatements with particular firms, but there are no data available to include those agreements in the analysis. ${ }^{36}$ Furthermore, even if data on tax abatement agreements were available, we would need investment data by firm (and not only by state as we have) to include those agreements correctly.

Table 1 shows summary statistics of the data. The mean corporate tax rate is $6.6 \%$ with a range between $0 \%$ and $12.7 \%$, which provides good tax variation across states to estimate tax effects. Still, we have to take into account the fact that some states allow corporations to deduct

\footnotetext{
${ }^{36}$ Papke (1995), using site and firm specific data from six midwest states, examines the impact that tax incentives (investment tax credits and property tax abatements) have on the after-tax rate of return. He finds that tax incentives have very modest effects on the net returns to new investment. Specifically, he finds that a $50 \%$ property tax abatement for new machinery and equipment "...has a neglible incremental impact on the baseline after-tax rate of return".
} 
their federal tax liabilities. In those cases we multiply the state corporate tax rate by $(1-$ federal top statutory corporate tax rate). ${ }^{37}$ This variable is called Etaxrate in Table 1 and is the one we use in the empirical work.

We also need to consider the source country tax regime. Multinational firms potentially have to paid taxes in every country and/or state where they are located and also in their home country. As a way of reducing double taxation on the foreign investments of these firms, governments use two different tax systems: foreign-tax-credit and exemption. Countries using a foreign-tax-credit system tax firms based on their worldwide earnings but allow a credit for taxes paid to foreign governments (Japan and United Kingdom in this sample). Countries using an exemption system directly exempt foreign income from home-country taxation (Australia, Canada, France, Germany, Netherlands and Switzerland in this sample). As a result, investment from countries with an exemption system should be more sensitive to corporate income taxes. We use a dummy variable for distinguishing these two tax regimes, the variable Credit Country is equal to 1 if the source country has a credit tax regime and 0 if it has an exemption tax regime.

An important aspect of the states' tax system is the use of different formulas to allocate the national profits of a firm among all the states where it operates. Almost all states use a three factor apportionment formula, which allocates the firm's profits based on its location of property, sales and payroll. McLure (1981) showed that the use of the apportionment formula basically transforms the state corporate income tax into three separate taxes on the factors consider in the formula. Given that the data we are using as a measure of investment is property, plant and equipment, we consider the weight given by each state to the property factor in the apportionment formula. The

\footnotetext{
${ }^{37}$ Eight states in 1974, six in 1980, seven in 1987, five in 1992, and three in 1997.
} 
variable apportionment then, is just the weight assigned to property in the apportionment formula of each state.

Table 1: Summary Statistics

\begin{tabular}{lccccc}
\hline Variable & Obs. & Mean & Std. Dev. & Min & Max \\
\hline Real PPE (\$ millions) & 1555 & 1119.38 & 2170.19 & 0 & 35419.8 \\
$\mathrm{~S}_{j t}$ & 1555 & 0.005 & 0.009 & 0 & 0.0893 \\
State Corporate Tax Rate & 1750 & 0.0663 & 0.0287 & 0 & 0.1265 \\
Etaxrate & 1750 & 0.06314 & 0.0281 & 0 & 0.1265 \\
Population (in thousands) & 1750 & 4874.42 & 5254.14 & 344 & 32182.12 \\
Real Wage (\$ per hour) & 1750 & 13.476 & 1.81 & 9.96 & 21.81 \\
Road per Area (mile $\left.{ }^{-1}\right)$ & 1750 & 1.609 & 1.16 & 0.09 & 6.12 \\
Real Price of Energy & 1750 & 7.40 & 2.50 & 2.83 & 16.70 \\
Revenue Limit & 1750 & 0.089 & 0.285 & 0 & 1 \\
Expenditure Limit & 1750 & 0.334 & 0.472 & 0 & 1 \\
Legislature & 1750 & 0.489 & 0.50 & 0 & 1 \\
Credit Country & 1750 & 0.2857 & 0.4519 & 0 & 1 \\
Apportionment & 1750 & 0.2875 & 0.0835 & 0 & 0.333 \\
Domestic Fixed Capital Investment & 1750 & 260920 & 315710 & 24357 & 1296402 \\
\hline
\end{tabular}

The variables Expenditure Limit and Revenue Limit are dummies equal to one if the state has a constitutional or statutory provision that constraints the annual growth of expenditures and revenues respectively, and zero otherwise. The variable Legislature is equal to one if the state legislature must pass a balanced budget, and zero otherwise.

There are some public goods provided by the state that help business activity, like infrastructure, for example. As a measure of this type of public goods we use the variable road per area, which is calculated as the total number of miles of roads in each state divided by its area (measured in squared miles).

The variables Real Wage and Real Price of Energy represent the prices of other inputs in the production process and therefore, considered and demanded by foreign investors. Real wages are the state average wage in manufacturing measured in dollars per hour, deflated by CPI, and the 
real price of energy is an index published by the Bureau of Labor and Statistics, also deflated by CPI.

Table 2 shows summary statistics for the corporate tax rate by year. ${ }^{38}$ As we can see, the mean and the median tax rate have been increasing over time, and the standard deviation has been decreasing since 1987. This might be a symptom of some degree of collusion rather than one of tax competition, but that is an empirical question beyond the scope of this paper.

Table 2: States Corporate Tax Rate by Year

\begin{tabular}{llllll}
\hline Year & Mean & Std. Dev. & Median & Min. & Max. \\
\hline 1974 & 0.0594 & 0.0284 & 0.06 & 0 & 0.12 \\
1980 & 0.0622 & 0.0295 & 0.06 & 0 & 0.12 \\
1987 & 0.0676 & 0.0303 & 0.07 & 0 & 0.12 \\
1992 & 0.0710 & 0.0293 & 0.0781 & 0 & 0.1265 \\
1997 & 0.0705 & 0.0271 & 0.076 & 0 & 0.12 \\
\hline
\end{tabular}

Table 3 shows the changes in the state corporate tax rates over time. If we look at the whole period 1974-1997, we have that 29 states had a higher corporate tax rate in 1997 compared to the one they had in 1974, 7 have a lower one, and 14 states have exactly the same one. If we split the period in two, we can see that more states increased their tax rates between 1974 and 1987 than between 1987 and 1997 (27 compared to 15). The opposite is true in terms of decreases in the tax rate (11 states compared to only 5 ). This table may suggest that the degree of competition (collusion) was lower (higher) between 1974 and 1987 and that after 1987 (at least compared to the previous period).

\footnotetext{
${ }^{38}$ There are four states that have had a zero tax rate over the whole period (Nevada, South Dakota, Washington and Wyoming) and seven states that have never changed their tax rate during this period.
} 
Table 3: Tax Rates Variation

\begin{tabular}{llll}
\hline & $1974-97$ & $1974-87$ & $1987-97$ \\
\hline Increases & 29 & 27 & 15 \\
Mean Increased & 0.0225 & 0.0213 & 0.01163 \\
Reductions & 7 & 5 & 11 \\
Mean Reduction & 0.0155 & 0.0236 & 0.00732 \\
No Change & 14 & 18 & 24 \\
\hline
\end{tabular}

\section{Results}

Table 4 shows the Interval regressions ${ }^{39}$ of equation (16). Model (1) uses the statutory corporate tax rate directly as a variable to capture tax effects, and the models (2) to (5) use the set of budget limits dummies described before as instrumental variables to control for the endogeneity of the tax rate. $^{40}$ The first regression (model (1)) shows a negative relationship between FDI share and state's corporate tax rate, but the coefficient is not significant, and the elasticities implied are quite low. The tax elasticity, calculated at mean and median values, is -0.19 and -0.2 respectively.

Model (2) has the same specification of model (1) but corrects for the possible tax endogeneity using instrumental variables. Now, the coefficient of the state's tax rate is -16.911 , which implies a tax elasticity of -1.06 at the mean values and -1.11 at the median values. ${ }^{41}$ This result shows an upward bias that occurs when tax effects are estimated without taking tax endogeneity into account. This is consistent with the results in the literature that have shown very small or zero tax effects.

\footnotetext{
${ }^{39}$ The reason to use Interval Regression estimation is because $12.8 \%$ of the investment data in the sample are missing. Recall that these missing data represents positive amounts of investment, but no specific amounts are reported by the BEA (11.1\% due to confidentiality reasons and $1.7 \%$ because the amount invested is less than $\$ 500,000)$.

${ }^{40}$ For the first regression standard errors were calculated using the Huber-White estimator. For the regression in which we use instrumental variables, we calculated the standard errors for the second stage using bootstrapping with 1000 repetitions. In all regressions the standard errors are calculated clustering by state.

${ }^{41}$ Hausman tests rejects the exogeneity of the tax rate in model (1) and the overidentification test in model (2) does not reject the validity of the IV.
} 
A corporate income tax elasticity of -1 means that a one percent increase in a state corporate tax rate would decrease, on average, the share of FDI received by a state in $1 \%$, ceteris paribus.

Table 4: FDI Equations

\begin{tabular}{lccccc}
\hline $\ln \left(s_{j t}\right)-\ln \left(s_{o t}\right)$ & $(1)$ & $(2)$ & $(3)$ & $(4)$ & $(5)$ \\
\hline Corporate Tax Rate & -3.020 & -16.911 & -18.079 & -8.725 & -9.959 \\
& $(4.708)$ & $(4.627)$ & $(4.803)$ & $(4.459)$ & $(4.633)$ \\
Tax Rate $\times$ Credit Count. & & & 5.619 & & 5.489 \\
& & & $(8.394)$ & & $(8.072)$ \\
Tax Rate $\times$ Apportionm. & & & -22.973 & -22.702 \\
& & & $(8.780)$ & $(9.110)$ \\
Credit Country & & & -0.584 & & -0.575 \\
& & & $(0.563)$ & & $(0.546)$ \\
Population & 0.000175 & 0.000183 & 0.000182 & 0.000179 & 0.000178 \\
& $(0.00002)$ & $(0.000008)$ & $(0.000009)$ & $(0.000009)$ & $(0.000009)$ \\
Real Wage & -0.0260 & -0.0287 & -0.0262 & -0.0324 & -0.0299 \\
& $(0.0510)$ & $(0.0292)$ & $(0.0298)$ & $(0.0287)$ & $(0.0284)$ \\
Real Energy Price & -0.1166 & -0.1067 & -0.1070 & -0.0995 & -0.0998 \\
& $(0.0342)$ & $(0.0215)$ & $(0.0225)$ & $(0.0232)$ & $(0.0230)$ \\
Road per Area & 0.3261 & 0.458 & 0.4482 & 0.4317 & 0.4223 \\
& $(0.1516)$ & $(0.0720)$ & $(0.0684)$ & $(0.0721)$ & $(0.0688)$ \\
Constant & -6.329 & -5.753 & -5.6196 & -5.792 & -5.665 \\
& $(0.8326)$ & $(0.4631)$ & $(0.4760)$ & $(0.4797)$ & $(0.4589)$ \\
\hline Wald Chi ${ }^{2}$ & 106.91 & 117.16 & 96.86 & 122.92 & 126.12 \\
Log Likelihood & -3131.11 & -3121.01 & -3125.44 & -3125.59 & -3122.61 \\
Observations & 1555 & 1555 & 1555 & 1555 & 1555 \\
\hline$\eta$ & -0.1906 & -1.0676 & & -0.9631 & \\
$\eta_{\text {exempt }}$ & $(0.2972)$ & $(0.2953)$ & & $(0.2718)$ & \\
$\eta_{\text {credit }}$ & & & -1.1413 & & -1.0361 \\
& & & $(0.2975)$ & & $(0.3018)$ \\
\hline Nimbers & & -0.7866 & & -0.6896 \\
& & & $(0.5152)$ & & $(0.5370)$ \\
\hline
\end{tabular}

Numbers in parenthesis are standard errors. All the regressions include year dummies.

The coefficients for the population and road per area variables are both positive, significant, and with the expected sign. Total population in one state captures in some way the level of business 
activity; therefore, it should have a positive impact on the amount of FDI the state receives. ${ }^{42}$ The elasticity at the mean is 0.912 , which means that a $1 \%$ increase in the population of a state would increase its FDI share on average by $0.9 \%$, ceteris paribus. The number of miles of roads per area measures the level of a public good provided by the state that helps business activity; thus it should also have a positive impact on FDI. The implied elasticity evaluated at the mean is 0.733 which implies that a $1 \%$ increase in the miles of roads per area would increase, on average, the share of FDI by $0.73 \%$, ceteris paribus. The real price of energy captures the cost of some of the non-labor inputs of production; therefore, the negative and significant coefficient for that variable in the regressions is the expected one. The elasticity at the mean is -0.786 , what implies that an increase in the real price of energy of $1 \%$ would decrease the share of FDI by $0.78 \%$ on average.

The coefficient for the wage variable is negative but not significant. A negative sign would be expected if higher wages increase the costs of a firm and, therefore, decrease its profits. One possible explanation for the non-significance finding is that the real wage variable is also capturing higher productivity of the labor force. Therefore, we decided to include a variable for education in the regression, and, for this purpose, we used the number of high school graduates per capita. The coefficient on the education variable was positive and not significant in the regression, and the size of the coefficient for wages was reduced to half and was still not significant. ${ }^{43}$ If we use education instead of wages in the regression, the coefficient on education is positive and not significant, and the other coefficients and standard errors are almost identical. We decided, then, to report the regression with wages instead of education because it should reflect labor costs better.

\footnotetext{
${ }^{42}$ We also tried real retail sales by state instead of population, and the results were very similar.

${ }^{43}$ The correlation between the education and wage variables is -0.6339 .
} 
The elasticity with respect to wages, even though it is not significant, is -0.385 , which implies that a $1 \%$ increase in the real wage in a state would decrease its FDI share by $0.38 \%$.

Model (3) adds to model (2) the credit country dummy, alone and interacted with the tax rate. The inclusion of these two variables attempts to control for the tax regime of the source country and its effects on the effective state tax rate faced by investors from these two different tax regimes. The coefficient for the tax rate is -18.08 , which implies a tax elasticity of -1.14 at mean values and -1.19 at median values for investment from countries using an exemption regime. As expected, the coefficient for the credit country dummy interacted with the tax rate is positive, showing that investors from countries using credit regimes are less sensitive to corporate income tax rates. The tax elasticity for credit countries is -0.79 at mean values and -0.82 at median values. However, the coefficient for this variable is not statistically different from zero, and the tax elasticity is not statistically different from the one for exemption countries. The credit country dummy alone is negative, but is also non statistically different from zero.

Model (4), following the theoretical results of McLure (op. cit), adds to model (2) the property weight in the apportionment formula interacted with the tax rate. The coefficient of this variable is -22.97 and is statistically significant. The elasticity of the share of FDI from country $s$ that state $j$ receives $\left(s_{s j}\right)$ is -0.412 at mean values, and -0.5 at median values. The implication of this result is that if a state increases the weight of the property factor in its apportionment formula, the share of total FDI received by that state would decrease around half percent on average, ceteris paribus. Now, the coefficient of the corporate tax rate is -8.73 , it is statistically significant but its size is half as before (compared with model (2)). The tax elasticity calculated at mean values is -0.96 and calculated at median values is -1.08 , both very similar to the ones estimated without 
considering the effect of the apportionment formula. These results show that the property factor in the apportionment formula has an important impact on the effective state corporate income tax rate that investors face and, therefore, on the fraction of FDI that states receive. However, in terms of the corporate income tax elasticity, controlling for the apportionment system does not change the results obtained when only the top statutory tax rate is used. ${ }^{44}$

Finally, model (5) controls for both, the apportionment formula and the tax regime of the source country. The coefficient for the corporate tax rate is statistically significant and higher than in model (4), but still around half the size compared to models (2) and (3). The effect of the property weight of the apportionment formula interacted with the tax rate is again negative and significant. The FDI share elasticity with respect to the property weight of the apportionment formula is -0.407 at mean values and -0.498 at median values, basically identical as before (model (4)). The coefficient for the credit country dummy variable interacted with the state tax rate, as in model (3), has the expected sign but it is not significant. The tax elasticity for an exemption country is -1.06 and for a credit country is -0.69 , both at mean values, although the elasticity for credit countries is not statistically different than the one for exemption countries.

Table 5 shows the results of the first-stage regression corresponding to model $(2) \cdot{ }^{45}$, ${ }^{46}$ The coefficients on the variables Revenue Limit and Expenditure Limit are both negative and statistically significant, showing that state governments that face constraints to the annual growth of its expenditures and revenues set lower taxes than states that do not have these limits. The coefficient

\footnotetext{
${ }^{44}$ Hines (1996) also estimates the effects of corporate income tax on FDI with and without correction for apportionment system. He finds no difference in the results.

${ }^{45}$ The first-stage regressions corresponding to models (2) to (5) show similar results.

${ }^{46}$ The first-stage regression includes all the exogenous variables of the model, but the coefficients and standard errors for the variables real wages, real price of energy, population and roads per area are not reported in the table.
} 
on the Legislature variable is positive and significant, which shows that states whose legislatures must enact a balanced budget have higher taxes. The F-test of joint significance of the three variables we used as instruments is 97.18 , which strongly rejects the hypothesis of non-significance. Furthermore, every instrument by itself is highly significant. ${ }^{47}$

\begin{tabular}{ll} 
Table 5: IV First-Stage Regression \\
\hline Corporate Tax Rate & OLS \\
\hline Revenue Limit & -0.0271 \\
& $(0.0018)$ \\
Expenditure Limit & -0.0037 \\
& $(0.0013)$ \\
Legislature & 0.0046 \\
& $(0.0015)$ \\
Constant & 0.0290 \\
& $(0.0051)$ \\
\hline Adjusted $\mathrm{R}^{2}$ & 0.3735 \\
F(all) & 121.72 \\
F(IVs) & 97.18 \\
Observations & 1555
\end{tabular}

Numbers in parenthesis are standard errors

As we had mentioned it at the end of section 2.1, the tax elasticity in this model is driven by the functional form assumption about how the tax rate enters the profit function. Therefore, to check the robustness of our results, we estimated the same five models again, assuming this time a log-linear profit function. The results were vey similar and the estimated tax elasticities were slightly larger. ${ }^{48}$

Finally, it is also important to consider the role of the outside option in these results. For this purpose, we estimated equation (16) again without including the outside option. ${ }^{49}$ Table 6 compares

\footnotetext{
${ }^{47}$ We also estimated the first stage equation using every instrument alone and every combination of two of them and then we performed likelihood ratio and Hausman tests among the different specifications, and the unrestricted model was always prefered.

${ }^{48}$ The results are available from the authors upon request.

${ }^{49}$ We used the same procedure and the same instrumental variables, but $s_{i j t}$ was calculated over the total investment
} 
the estimated elasticities, for model (2), evaluated at the means with and without considering the outside option. As can be seen from the table, when no outside option is considered the estimated tax elasticity is lower. Even though this bias might be small, its direction is consistent with what the theory predicts, investors with no outside options would be less sensitive to tax changes.

\begin{tabular}{ccc}
\multicolumn{3}{c}{ Table 6: Tax Elasticities at Mean Values } \\
\hline & Outside Option & No Outside Option \\
\hline Tobit & -0.1897 & -0.174 \\
& $(0.2918)$ & $(0.1331)$ \\
Tobit-IV & -1.0624 & -0.866 \\
& $(0.2939)$ & $(0.1972)$ \\
\hline
\end{tabular}

Standard errors are in parenthesis.

Our results show a robust, negative, and statistically significant tax elasticity for foreign direct investment when tax endogeneity and investors' outside options are considered. The estimated elasticity is larger in absolute value compared to what other studies have found.

\section{Conclusion}

In this paper, we have used a Logit Model of demand adapted from the discrete-choice literature to investigate the effects of corporate taxes on investment location. Theoretically taxes should have a negative impact on investment location, unless they represent a fiscal package that includes greater amounts of public goods and services that benefit investment, in which case the total package might have a positive impact. The empirical literature shows mixed results; most of the studies find no tax effects; some of them, a negative effect, and some others show a positive effect. The question,

of each country in the US (instead of total investment in the US plus total investment in their own countries). The dependent variable in the equation was $\ln \left(s_{i j t}\right)$ instead of $\ln \left(s_{i j t}\right)-\ln \left(s_{o t}\right)$. 
then, is whether the theoretical models are not capturing very well how investors take decisions or whether the empirical work is missing something, or both. We do not pretend to give a final answer to this question, but with this study we do want to highlight the importance of considering tax endogeneity and the existence of outside options for the empirical work in this matter.

The evidence presented in this paper shows that state governments do consider some of the state characteristics that might be attractive (or not) to investors when setting taxes. Ignoring the tax setting behavior of state governments then, may bias the estimate of the tax effects on FDI. Using states' statutory and constitutional budget limits as instrumental variables and explicitly allowing an outside option for investors, we correct for this bias. We also consider in the empirical analysis the effects of the apportionment formula used by the state governments to allocate the national profits of a firm among all the states where it operates, and the effects of the source country tax regime. The results show that the property factor in the apportionment formula has an important impact on the effective state corporate income tax rate that investors face and, therefore, on the fraction of FDI that states receive. However, in terms of the corporate income tax elasticity, controlling for the apportionment system does not change the results obtained when only the top statutory tax rate is used. Even though the sign of the coefficient is the expected one, the elasticity for credit countries is not statistically different than the one for exemption countries. Overall, we find the FDI to be quite sensitive to states' corporate tax rates. The estimated tax elasticity is estimated consistently around -1 . 


\section{References}

Alt, James E. and Robert C. Lowry, (1994), "Divided Government, Fiscal Institutions, and Budget Deficits: Evidence from the States", American Political Science Review 88, 811-828.

Bartik, Timothy, (1991), "Who Benefits from State and Local Development Policies?", Upjohn Institute for Employment Research, Kalamazoo, Michigan.

Berry, S., (1994), "Estimating Discrete Choice Models of Product Differentiation", Rand Journal of Economics 25, 242-262.

Berry, S., J. Levinsohn and A. Pakes, (1995), "Automobile Prices in Market Equilibrium", Econometrica 63, 841-890.

Berry, S., J. Levinsohn and A. Pakes, (1998), "Differentiated Products Demand Systems from a Combination of Micro and Macro Data: The New Car Market", NBER Working Paper No. 6481. Besley, Timothy, and Anne Case, (1995), "Incumbent Behavior : Vote Seeking, Tax-Setting and Yardstick Competition", American Economic Review 85, 25-45.

Bohn, Henning and Robert P. Inman, (1996), "Balanced-Budget Rules and Public Deficits: Evidence from the U.S. States", Carnegie-Rochester Conference Series on Public Policy 45, 13-76.

Case, Anne C., James R. Hines, Jr. and Harvey S. Rosen, (1993), "Budget Spillovers and Fiscal Policy Interdependence: Evidence from the States", Journal of Public Economics 52, 285-307.

Carlton, Dennis W., (1983), "The Location and Employment Choices of New Firms: an Econometric Model with Discrete and Continuous Endogenous Variables", Review of Economics and Statistics 65, 440-449.

Crain, W. Mark and James C. Miller III, (1990), "Budget Process and Spending Growth", 
William and Mary Law Review 31, 1021-1046.

Coughlin, Cletus C., Joseph V. Terza and Vachira Arromdee, (1991), "State Characteristics and the Location of Foreign Direct Investment within the United States", Review of Economics and Statistics 73, 675-683.

Council of State Governments. The Book of the States. Several years.

Hendel, Igal, (1999), "Estimating Multiple-Discrete Choice Models: An Application to Computerization Returns", Review of Economic Studies 66, 423-446.

Hines, James R., Jr., (1996), "Altered States: Taxes and the Location of Foreign Direct Investment in America", American Economic Review 86, 1075-1094.

Huber, Bernd, (1999), "Tax Competition and Tax Coordination in an Optimum Income Tax Model", Journal of Public Economics 71, 441-458.

Ladd, Helen F. (1998), "Effects of Taxes on Economic Activity, in "Land Government Tax and Land Use Policies in the United States", Edward Elgar Publishing, Northampton, Massachusetts.

Luger, M. and S. Shetty, (1985), "Determinants of Foreign Plant Start-ups in the United States: Lessons for Policymakers in the Southeast", Vanderbilt Journal of Transnational Law Spring, 223245.

McFadden, Daniel, (1974), "Conditional Logit Analysis of Qualitative Choice Behavior", in: Paul Zarembka ed., Frontiers in Econometrics (New York Academic Press).

Maddala, G.S., (1983), "Limited Dependent and Qualitative Variables in Econometrics", Cambridge University Press.

Moore, Michael, Bert Steece and Charles Swenson, (1987), "An Analysis of the Impact of State Income Rates and bases on Foreign Investment", Accounting Review 62, 671-685. 
Nevo, Aviv, (2000), "A Practitioner's Guide to Estimation Random Coefficients Logit Models of Demand", Journal of Economics and Management Strategy 9, 513-548.

Nevo, Aviv, (2001), "Measuring Market Power in the Ready-to-Eat Cereal Industry", Econometrica 69, 307-342.

Ondrich, Jan and Michael Wasylenko, (1993), "Foreign Direct Investment in the United States", Upjohn Institute for Employment Research, Kalamazoo, Michigan.

Papke, James, (1995), "The Convergence of State-Local Business Tax Costs: Evidence of De Facto Collaboration", Proceedings of the Eighty-Eighth Annual Conference on Taxation, San Diego, CA, National Tax Association-Tax Institute of America.

Papke, Leslie E., (1991), "Interstate Business Tax Differentials and New Firm Location. Evidence from Panel Data", Journal of Public Economics 45, 47-68.

Poterba, James M., (1994), "State Responses to Fiscal Crises: The Effects of Budgetary Institutions and Politics", Journal of Political Economy 102, 799-821.

Poterba, James M., (1995), "Balanced Budget Rules and Fiscal Policy: Evidence from the States", National Tax Journal 48, 329-337.

Ray, Edward J., (1977), "Foreign Direct Investment in Manufacturing", Journal of Political Economy 85, 283-297.

Rork, Jonathan, (2000), "Neighboring Influences in State Tax Determination". Proceedings of the 93rd Annual Conference on Taxation, Santa Fe, NM, National Tax Association, 291-294.

Rueben, Kim S., (1997), "Tax Limitations and Government Growth: The Effect of State Tax and Expenditure Limits on State and Local Government", Ph.D. Dissertation, MIT Department of Economics. 
U.S. Department of Commerce, Bureau of Economic Analysis, "Foreign Direct Investment in the United States", Benchmark Survey for the years 1974, 1980, 1987, 1992 and 1997.

Wasylenko, Michael, (1997), "Taxation and Economic Development: The State of the Economic Literature", New England Economic Review, 36-52.

Woodward, Douglas, (1992), "Locational Determinants of Japanese Manufacturing Start-ups in the United States", Southern Economic Journal 58 3, 690-708. 